\title{
A Digital Method for the Detection of Blood Flow Direction in Ultrasonic Doppler Systems
}

\author{
Método digital para la detección de la dirección \\ de flujo sanguineo en sistemas doppler ultrasónicos
}

\author{
A. Sotomayor-Ortega \\ Instituto de Investigaciones en Matemáticas Aplicadas y en Sistemas, DISCA, \\ Universidad Nacional Autónoma de México. \\ E-mail:soto@uxdea4.iimas.unam.mx \\ M. Fuentes-Cruz \\ Instituto de Investigaciones en Matemáticas Aplicadas y en Sistemas, DISCA, \\ Universidad Nacional Autónoma de México. \\ E-mail:martin@uxdea4.iimas.unam.mx \\ F. García-Nocetti \\ Instituto de Investigaciones en Matemáticas Aplicadas y en Sistemas, DISCA, \\ Universidad Nacional Autónoma de México. \\ E-mail:fabian@uxdea4.iimas.unam.mx \\ E. Moreno-Hernández \\ Instituto de Cibernética Matemáticas y Física, CENUS. \\ La Habana, Cuba. \\ E-mail:moreno@icmf.inf.cu \\ M. Barragán-Ocampo \\ Instituto de Investigaciones en Matemáticas Aplicadas y en Sistemas, DISCA, \\ Universidad Nacional Autónoma de México. \\ E-mail:miguel@uxdea4.iimas.unam.mx \\ P. Acevedo-Contla \\ Instituto de Investigaciones en Matemáticas Aplicadas y en Sistemas, DISCA, \\ Universidad Nacional Autónoma de México. \\ E-mail:pedro@uxdea4.iimas.unam.mx
}

(Recibido: enero de 2007; aceptado: febrero de 2008)

\begin{abstract}
Doppler ultrasound systems are widely used to study blood flow and diagnosis of vascular diseases. An important characteristic of these systems is the ability to detect the direction of the blood flow. Most Doppler ultrasound systems apply a quadrature demodulation technique on the ultrasonic transducer output signal. Therefore additional treatment is necessary to separate forward and reverse flow signals. This work presents a digital method to convert signals in quadrature into directional signals using a Fast Fourier Transform (FFT) approach. Validation of the method has been achieved usingsimulatedDopplerultrasound signals.
\end{abstract}

Keywords: Signal analysis, direction detection, Dopper ultrasound. 
DOI: http://dx.doi.org/10.22201/fi.25940732e.2010.11n1.002

A Digital Method for the Detection of Blood Flow Direction in Ultrasonic Doppler Systems

\section{Resumen}

Los sistemas Doppler ultrasónicos se utilizan ampliamente para el estudio del flujo sanguíneo y el diagnóstico de enfermedades vasculares. Este tipo de instrumentos cuenta con una característica muy importante que es la de poder detectar y discriminar la dirección del flujo sanguíneo. Por lo general, estos equipos utilizan la técnica de demodulación en cuadratura de la señal proveniente de un transductor ultrasónico, por lo que es necesario un tratamiento adicional para separar completamente las señales de flujo directo e inverso. Se presenta un método digital para la conversión de señales en cuadratura a direccionales, basado en la Transformada Rápida de Fourier (FFT), que es utilizada para la detección de la dirección del flujo sanguíneo en sistemas Doppler Ultrasónicos. El método ha sido validado utilizando señales Doppler ultrasónicas sintetizadas.

Desciptores: análisis de señales, detección de dirección, ultrasonido Doppler.

\section{Introduction}

At present Doppler ultrasound systems are widely used to study blood flow and diagnosis of vascular diseases. The wide use of these systems is mainly due to their noninvasive characteristics and their relative low cost. An important characteristic of the modern Doppler instruments is that these are able to obtain the direction of the blood flow in a accurate manner for which there are several proposed techniques. These equipments mainly use the demodulation in quadrature technique of the signal from the ultrasonic transducer (Evans et al., 2000). The result of this demodulation is two signals in quadrature which are filtered to eliminate the high frequency components. These signals known as signals in phase and in quadrature require an additional processing to be able to extract the blood flow direction (Evans et al., 2000) (Nizamettin, et al., 1994). Analogue methods have been typically used to perform this decodification basing its operation in the treatment of the signal in the phase and frequency domains. Diverse and novel algorithms have been proposed, showing the advantages of the digital techniques over the analogue techniques (Nizamettin and Evans, 1994, 1996), (Marple, 1999).

This work presents a digital method to convert signals in quadrature into directional signals (forward and reverse flows) using a FFT and IFFT transforms to implement the Complex Discrete Fourier Transform (CDFT) and the Inverse Complex Discrete Fourier Transform (ICDFT) respectively as shown in figure 1. The advantage of having on one side a signal in phase and on the other side a signal in quadrature is that we have the possibility to store the information of the forward and reverse flows in an independent form in the time domain, allowing to perform a detailed study of the behavior of the blood circulation within the

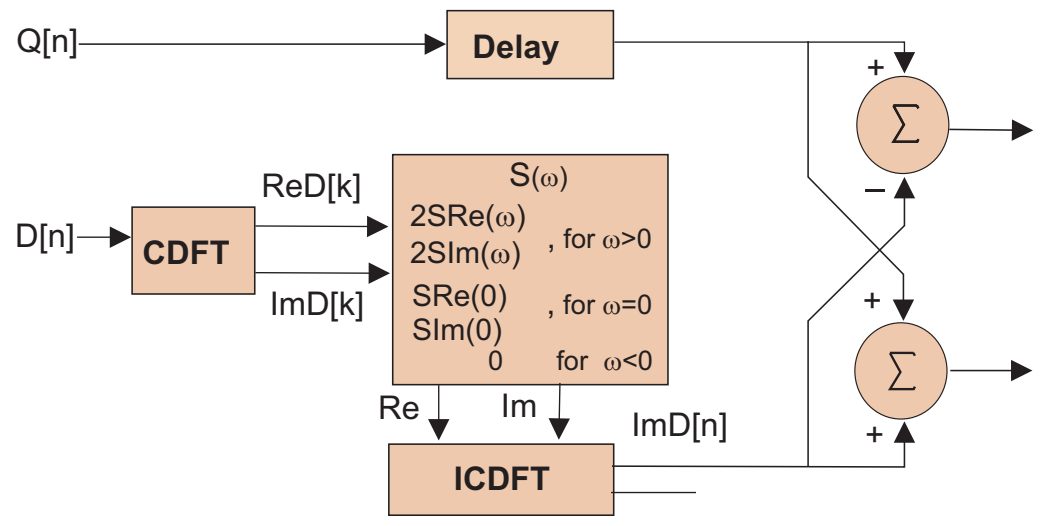

Figure 1. Block diagram of the algorithm in the time domain 
irradiated zone and to show in an independent way the flow in each direction.

\section{Description of the method}

The blood flow Doppler signal $x(t)$ has flow information in the forward and reverse direction for two signals in perfect quadrature and balanced in amplitude (Nizamettin and Evans, 1994).

$$
\begin{aligned}
& x(t)=d(t)+j q(t) \\
& x(t)=\left(\cos \omega_{f} t+\sin \omega_{r} t\right)+j\left(\sin \omega_{f} t+\cos \omega_{r} t\right)
\end{aligned}
$$

therefore:

$$
\begin{aligned}
& d(t)=\cos \omega_{f} t+\sin \omega_{r} t \\
& q(t)=\sin \omega_{f} t+\cos \omega_{r} t .
\end{aligned}
$$

The Doppler discrete signal can be modelled as a complex signal analytic (Vaitkus et al., 1988) as follows:

$$
X[n]=D[n]+j Q[n],
$$

where $D[n]$ and $Q[n]$ are the real signals in phase and in quadrature respectively in discrete time. Under conditions of stable flow, forward and reverse flow components can be implemented using the algorithm shown in figure 1, calculating the CDFT can be expressed as:

$$
\begin{aligned}
& D[k]=\operatorname{Re}[k]+j \operatorname{Im}[k] \\
& D[k]=\frac{1}{N} \sum_{n=0}^{N-1} D[n](\cos (2 \pi k n / N)-j \sin (2 \pi k n / N))
\end{aligned}
$$

where

$$
\begin{aligned}
& \operatorname{Re} D[k]=\frac{1}{N} \sum_{n=0}^{N-1} D[n] \cos (2 \pi k n / N) \\
& \operatorname{Im} D[k]=-\frac{1}{N} \sum_{n=0}^{N-1} D[n] \sin (2 \pi k n / N) .
\end{aligned}
$$

An analytic signal $s(t)$ in continuous time corresponding to a real signal of finite energy is defined in the frequency domain (Papoulis, 1977) as:

$$
S(\omega)=\left\{\begin{array}{cl}
2 S(\omega), & \text { for } 0 \leq \omega<\pi \\
S(0), & \text { for } \omega=0 \\
0, & \text { for } \omega<0
\end{array}\right.
$$

$$
\begin{aligned}
& \text { Calculating the ICFDT to obtain } D[n] \text { : } \\
& D[n]=\operatorname{Re} D[n]+j \operatorname{Im} D[n] \\
& D[n]=\sum_{k=0}^{N-1} \operatorname{Re} D[k](\cos (2 \pi k n / N)+j \sin (2 \pi k n / N)) \\
& -\sum_{k=0}^{N-1} \operatorname{Im} D[k](\sin (2 \pi k n / N)-j \cos (2 \pi k n / N)) \\
& \operatorname{Im} D[n]=-\sum_{k=0}^{N-1} \operatorname{Im} D[k](\sin (2 \pi k n / N)+j \cos (2 \pi k n / N)) .
\end{aligned}
$$

In the time domain:

$\operatorname{Im} d(t)=-\sin \omega_{f} t+j \cos \omega_{r} t$

from equations (4) y (14). Applying the proposed algorithm we have:

$$
\begin{aligned}
& F[n]=Q[n]-\operatorname{Im} D[n] \Rightarrow \sin \omega_{f} t+j \cos \omega_{r} t+\sin \omega_{f} t-j \cos \omega_{r} t \\
& F[n] \Rightarrow 2 \sin \omega_{f} t \text { forward flow. } \\
& R[n]=Q[n]+\operatorname{Im} D[n] \Rightarrow \sin \omega_{f} t+j \cos \omega_{r} t-\sin \omega_{f} t+j \cos \omega_{r} t \\
& R[n] \Rightarrow 2 \cos \omega_{r} t \text { reverse flow. }
\end{aligned}
$$

\section{Simulation}

To evaluate the performance of the implemented algorithm it was necessary to simulate a simple signal which includes the forward and reverse flow components:

$$
\begin{aligned}
& D(n)=\cos \left(\omega_{f} n\right)+\cos \left(\omega_{r} n\right) \\
& Q(n)=\sin \left(\omega_{f} n\right)-\sin \left(\omega_{r} n\right),
\end{aligned}
$$

where $\omega_{f}$ and $\omega_{r}$ represent the forward and reverse flow components, respectively. The reverse flow component was kept as a constant varying only the forward flow component (from $150 \mathrm{~Hz}$ to $8000 \mathrm{~Hz}$ ) calculating the level of separation using the following expression:

$$
\text { level_dB }=20 \log _{10}\left(\frac{R M S_{\text {reverse }}}{R M S_{\text {forward }}}\right) \text {. }
$$


Figure 2 shows the plot of the level of separation obtained with the implemented algorithm within the wideband under study. It is clearly seen that for frequencies under $1 \mathrm{KHz}$ the level of separation is within -54 and $-40 \mathrm{~dB}$, this is due to the method which introduces frequency components to the output signal due to the discontinuities caused by the effects of the borders of the applied window before the FFT calculation. However as the level of these signals and their harmonics are lower than $-40 \mathrm{~dB}$ the effect on these are negligible.

To display the corresponding spectrum of the signal under study a 2-D spectogram representation like the one shown in figure 3 was used, since this is the typical method used in ultrasonic Doppler systems.

To obtain this representation the Short Time Fourier Transform (STFT) was evaluated using $10 \mathrm{~ms}$ Hanning windows over consecutive segments of the signal. To minimize the effects of the data segmentation an overlap technique between windows was used

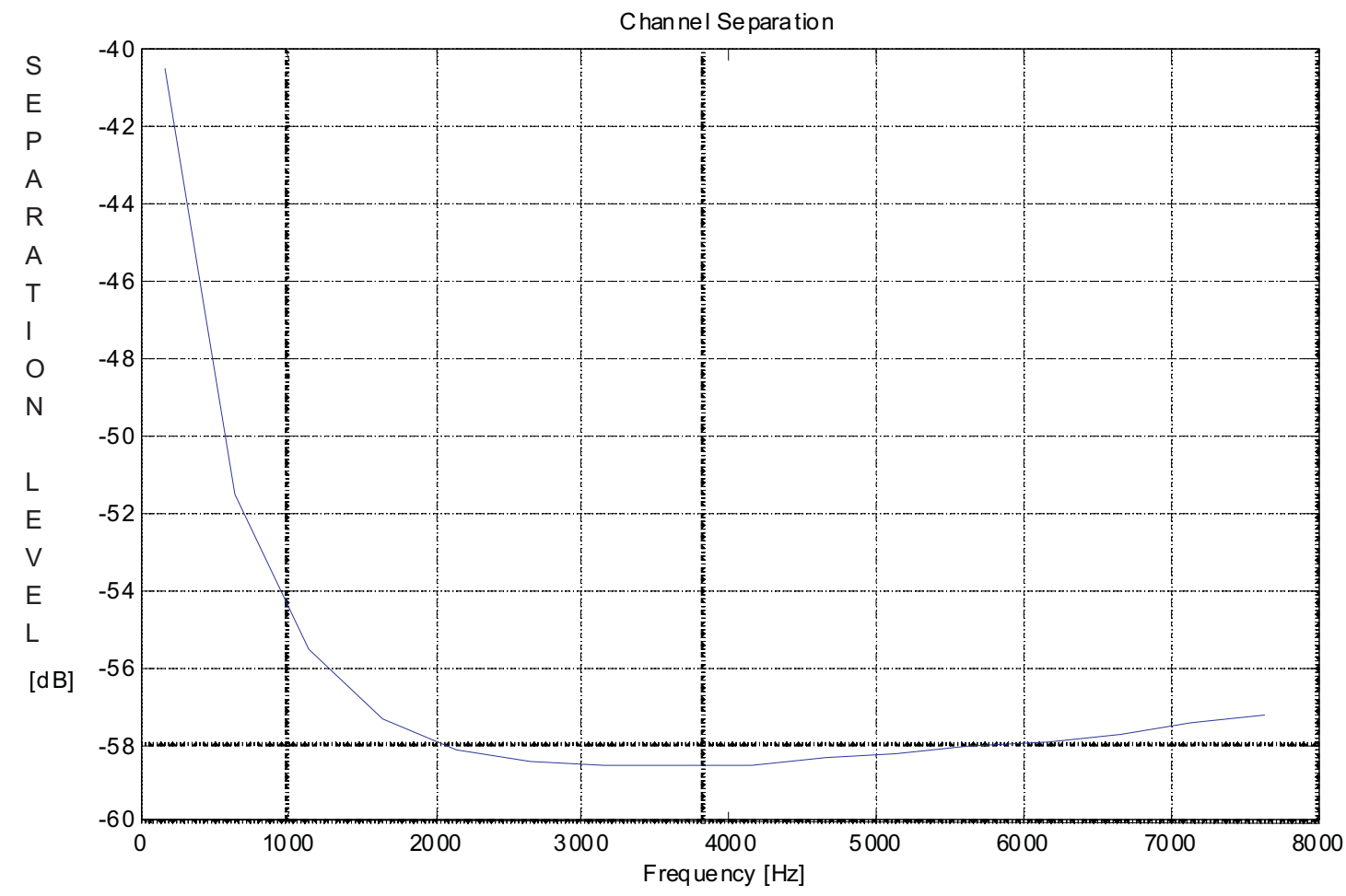

Figure 2. Level of separation of simulated signal

Table 1. Characteristics of the simulated signal using the FIELD II program

\begin{tabular}{lc}
\hline Sample frequency (fs) & $8 \mathrm{MHz}$ \\
\hline Transducer central frequency (fo) & $2 \mathrm{MHz}$ \\
Pulse Repetition Frequency (PRF) & $5 \mathrm{kHz}$ \\
Resolution & $16 \mathrm{bits}$ \\
Number of scatterers & 4990 \\
Vessel central position & $60 \mathrm{~mm}$ \\
Vessel radius & $4 \mathrm{~mm}$ \\
\hline
\end{tabular}




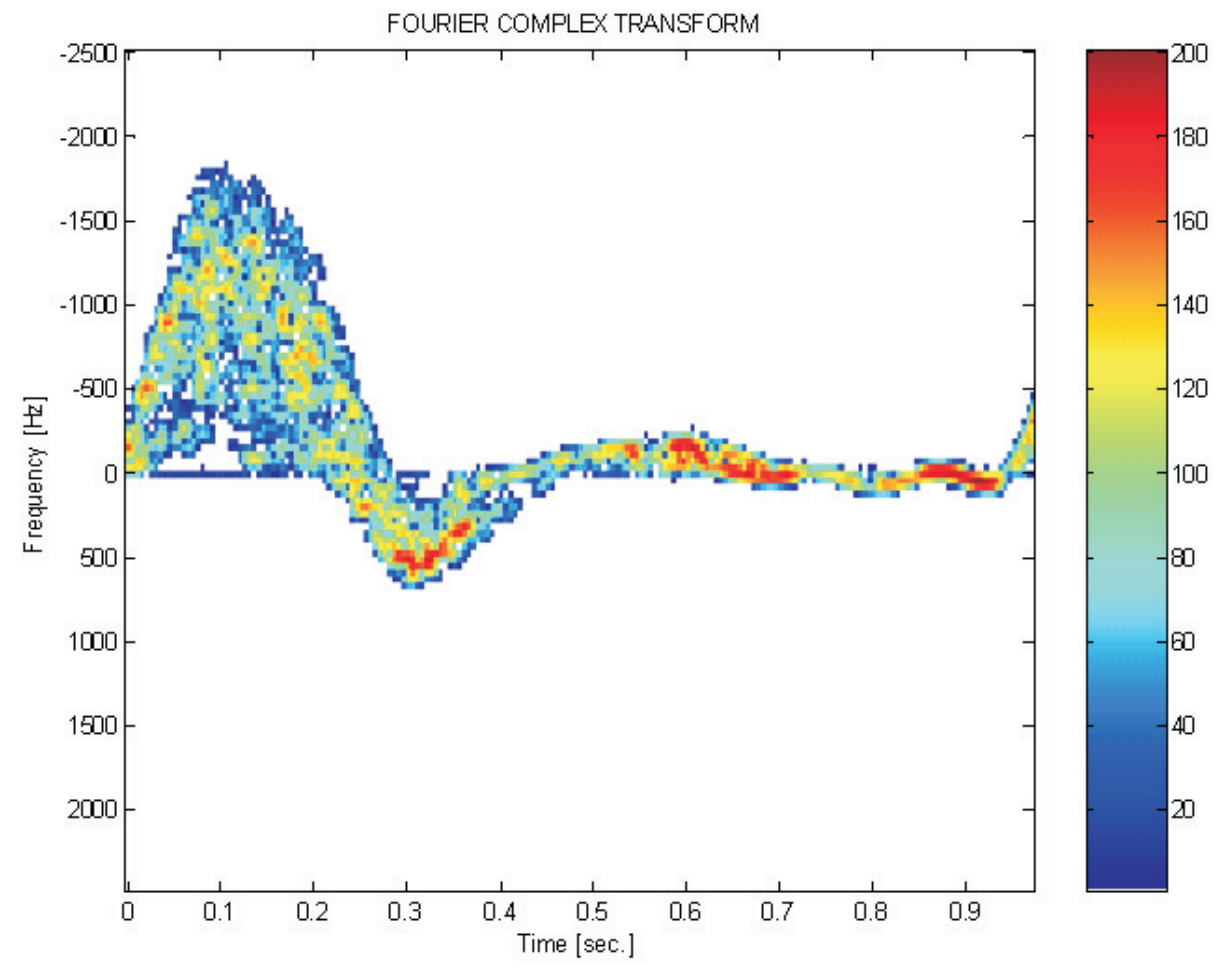

Figure 3. Spectogram of the simulated signal using the FIELD II program

allowing to minimize discontinuities present in the time domain.

Figure 3 shows the spectogram of the ultrasonic Doppler signal in a cardiac cycle.

\section{Results}

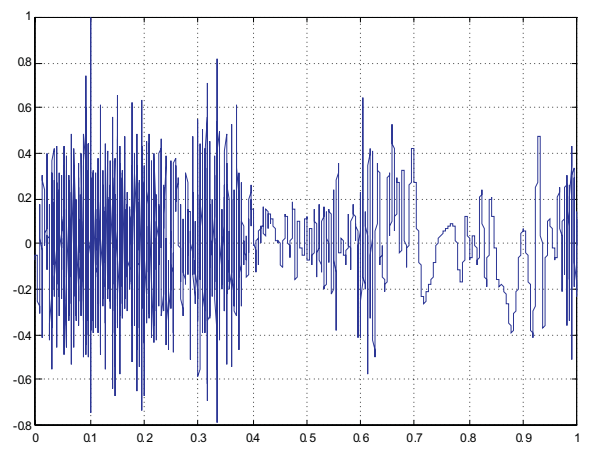

Figure 4 shows signals in quadrature $D(n)$ and $Q(n)$ for a cardiac cycle. These signals are obtained using demodulation in quadrature of the signal from the transducer (both signals are filtered to eliminate the high frequency components). Figure 5 shows the signals already separated after applying the described method, it is clearly observed the moment when the direction of

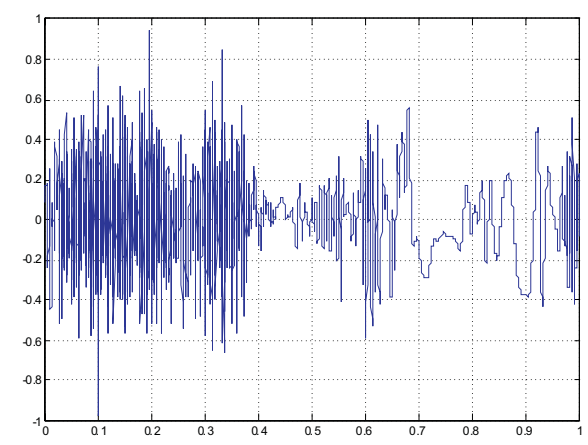

Figure 4. Simulated signals in quadrature 

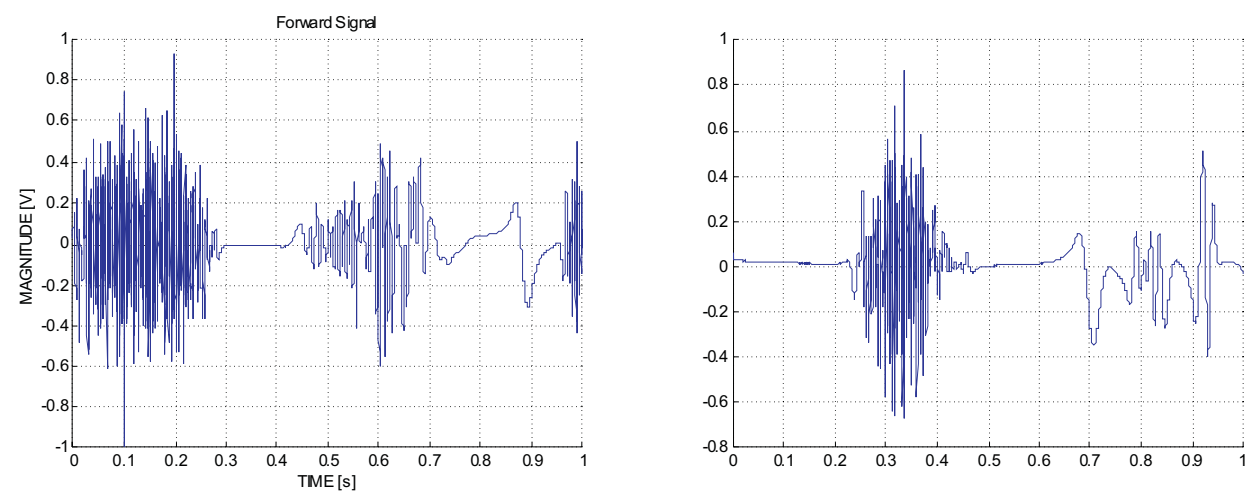

Figure 5. Forward and reverse flow signals obtained using the method

the flow changes in the time axe ( 0.25 to 0.4 seconds in figure 3$)$. It is worth mentioning that the level of separation was approximately $-56 \mathrm{~dB}$ within the bandwidth under study, this level is higher than ones reported in previous works.

\section{Conclusions}

The method described in this work requires basically the evaluation of a Fast Fourier Transform (FFT) and an Inverse Fast Fourier Transform (IFFT), therefore, this method can be implemented in a very efficient way on Digital Signal Processor (DSP) based architectures. It is worth mentioning that the level of separation of the forward and reverse flow signals obtained was around $-56 \mathrm{~dB}$ within the operation bandwidth, this result is a higher value than the values recently reported. It is also worth mentioning that the method was implemented on a bi-directional ultrasonic Doppler system based on a personal PC which is capable of processing and displaying in real time the forward and reverse flow signal spectograms in two independent windows as well as supplying this information in two separate audio outputs.

\section{Acknowledgements}

The authors acknowledge the support of UNAM (PAPIIT IN-109207 and IN-115007) in this work.

\section{References}

Evans D.H., McDicken W.N. Doppler Ultrasound, Physics, Instrumentation and Signal Processing. Second Edition. John Wiley \& Sons Ltd. 2000.

Jensen J.A. User's Guide for the Field II Program. Release 2.86, August 17. 2001.

Jensen J.A. Field: A Program for Simulating Ultrasound Systems. On: Med. Biol. Eng. Comp., 10th Nordic-Baltic Conference on Biomedical Imaging, Vol. 4, Supplement 1, Part 1, pp. 351-353. 1996.

Jensen J.A., Svendsen N.B. Calculation of Pressure Fields from Arbritarily Shaped, Apodized and Excited Ultrasound Transducers. IEEE Trans. Ultrason., Ferroelec., Freq. Contr., 39:262-267. 1992.

Papoulis A. Signal Analysis. New York. McGraw-Hill. 1977.

Vaitkus P.J., Cobbold R.S.C. Comparative Study and Assessment of Doppler Ultrasound Spectral Estimation. Part I Estimation Method. Ultrasound in Medicine and Biology, 14(8):661-672. 1988. 
DOI: http://dx.doi.org/10.22201/fi.25940732e.2010.11n1.002

A. Sotomayor-Ortega, M. Fuentes-Cruz, F. García-Nocetti, E. Moreno-Hernández, M. Barragán-Ocampo and P. Acevedo-Contla

\section{About the authors}

Alejandro Sotomayor-Ortega. He graduated in electronic engineering from the Instituto Superior Politécnico, Habana, Cuba in 1992. In 1994 he started working at the Instituto de Cibernética Matemática y Física, Cuba, at the Ultrasonic Center (CENUS-ICIMAF). In 1997 he obtained his master's degree in engineering from Universidad de la Habana, Cuba. In 2001 he started working at the Instituto de Investigaciones en Matemáticas Aplicadas y en Sistemas, UNAM. His research fields are: transducer design, ultrasonic instrumentation and signal processing applied to medicine and NDE.

Martín Fuentes-Cruz. He graduated in mechanical and electrical engineering from Facultad de Ingeniería, UNAM in 1984. He has worked at the Instituto de Investigaciones en Matemáticas Aplicadas y en Sistemas, UNAM sinced 1983. He has participated in several projects at and outside UNAM, this projects have been sponsored by: Instituto de Ciencias del Mar y Limnología, Instituto de Biología, Instituto de Geofísica, Universum Museum, Instituto Mexicano del Petróleo and CENUS- ICIMAF. He has been invited to several institutions in different countries such as: Spain, Cuba and Brazil. His research fields are: sismic instrumentation, meteorology, atmosferic monitoring and signal processing applied to medicine and industry.

Fabián García-Nocetti. He graduated in mechanical and electrical engineering from Facultad de Ingeniería, UNAM in 1984. He obtained his master and Ph. D. degrees in computing systems from the University of Wales, Bangor, U.K. in 1988 and 1991, respectively. He was awarded with the Premio Nacional de Ingeniería "Emilio Rosenblueth 1996", granted by the Academia Nacional de Ingeniería, and the award "Ciencia e Ingenería de la Computación" in 2000. At present he is investigador Titular B at IIMAS. His research fields are: high performance computing, signal and image processing, ultrasonic imaging, mobile computing and wireless networks.

Eduardo Moreno-Hernández. He graduated in physics from Facultad de Ciencias de la Universidad de La Habana. Since 1980 he works as researcher at the Instituto de Cibernética Matemática y Física, at the Ultrasonics Center (CENUS-ICIMAF), Cuba. In 1994 he obtained is Ph. D. in physics from Academia de Ciencias de Cuba. From 2000 to 2002, he worked as associated researcher at IIMAS-UNAM. At present he is head of project at CENUS-ICIMAF. His research fields are: signal and image processing and ultrasonic imaging.

Miguel Barragán-Ocampo. He graduated in electronic electric engineering from Facultad de Ingeniería, UNAM in 2002. He finished his bachelor dissertation at the Departamento de Ingeniería de Sistemas Computacionales y Automatización del IIMAS-UNAM. His research field is: signal and image processing.

Pedro Acevedo-Contla. He graduated in mechanical and electrical engineering from Facultad de Ingeniería, UNAM in 1984. He obtained his master's degree in electronic instrumentation in 1987 and his Ph. D. degree in ultrasonics in 1992, both from the University of Wales, Bangor, U.K. At present he is investigador titular A at IIMAS and lecturer at Facultad de Ingeniería, UNAM. He is a member of the Sistema Nacional de Investigadores-CONACYT. His research fields are: signal and image processing and ultrasonic imaging. 